\title{
A high density composite fuel with integrated burnable absorber: U3Si2-UB2
}

DOI:

10.1016/j.jnucmat.2019.151891

\section{Document Version}

Accepted author manuscript

Link to publication record in Manchester Research Explorer

\section{Citation for published version (APA):}

Turner, J., Middleburgh, S. C., \& Abram, T. (2019). A high density composite fuel with integrated burnable absorber: U3Si2-UB2. J. Nucl. Mater., 529(0), [151891]. https://doi.org/10.1016/j.jnucmat.2019.151891

\section{Published in:}

J. Nucl. Mater.

\section{Citing this paper}

Please note that where the full-text provided on Manchester Research Explorer is the Author Accepted Manuscript or Proof version this may differ from the final Published version. If citing, it is advised that you check and use the publisher's definitive version.

\section{General rights}

Copyright and moral rights for the publications made accessible in the Research Explorer are retained by the authors and/or other copyright owners and it is a condition of accessing publications that users recognise and abide by the legal requirements associated with these rights.

\section{Takedown policy}

If you believe that this document breaches copyright please refer to the University of Manchester's Takedown Procedures [http://man.ac.uk/04Y6Bo] or contact uml.scholarlycommunications@manchester.ac.uk providing relevant details, so we can investigate your claim.

\section{OPEN ACCESS}




\title{
A high density composite fuel with integrated burnable absorber: $\mathrm{U}_{3} \mathrm{Si}_{2}-\mathrm{UB}_{2}$
}

\author{
J. Turner ${ }^{1}$, S.C. Middleburgh ${ }^{2}$, T.J. Abram ${ }^{1}$ \\ ${ }^{1}$ Nuclear Fuel Centre of Excellence, The University of Manchester, United Kingdom \\ ${ }^{2}$ Nuclear Futures: Materials, Bangor University, Bangor, LL57 1UT, United Kingdom
}

\begin{abstract}
$\mathrm{UB}_{2}-\mathrm{U}_{3} \mathrm{Si}_{2}$ composite fuel pellets have been manufactured and characterised. Both main phases were observed to be stable in contact with one-another up to the maximum processing temperature of $1500^{\circ} \mathrm{C}$. The solubility and behaviour of hydrogen in $\mathrm{UB}_{2}$ was predicted and compared to previous work on the gas' behaviour in $\mathrm{U}_{3} \mathrm{Si}_{2} . \mathrm{H}_{2}$ was found to be insoluble in $\mathrm{UB}_{2}$ to any great extent, a clear distinction to the behaviour with $\mathrm{U}_{3} \mathrm{Si}_{2}$.
\end{abstract}

Keywords: Nuclear, Accident Tolerant Fuel, Burnable Absorber

\section{Introduction}

The nuclear accident at Fukushima Diachii has lead to extensive research into so-called Accident Tolerant Fuels (ATFs). These new combinations of fuel and cladding materials aim to offer significant advantages over the current $\mathrm{UO}_{2}$ fuel and zirconium cladding materials used predominantly in light water reactors. Potential advantages of the new systems include reduced fuel centre-line temperatures, higher power to melt ratios and improved oxidation performance under accident conditions with an associated reduction in hydrogen production.

A leading candidate ATF system is $\mathrm{U}_{3} \mathrm{Si}_{2}$ fuel pellets within a silicon carbide or chromium coated zirconium-alloy cladding. This has been the subject of considerable recent academic and industrial interest, which has culminated in a series of test irradiations at the Idaho National Laboratory [1,2]. $\mathrm{U}_{3} \mathrm{Si}_{2}$ has a higher uranium density than $\mathrm{UO}_{2}$, and an improved thermal conductivity. In concert with an advanced cladding solution such as $\mathrm{SiC}$, it therefore offers both economic and safety advantages over $\mathrm{UO}_{2} /$ zirconium. However, recent results suggest that the performance of $\mathrm{U}_{3} \mathrm{Si}_{2}$ in high temperature steam may be unacceptable, leading to the energetic pulverisation of the fuel pellet and rapid oxidation resulting in severe fuel failure [3].

This rapid pulverisation is thought to be a result of the unexpectedly high volume change which occurs when $\mathrm{U}_{3} \mathrm{Si}_{2}$ reacts with hydrogen to form $\mathrm{U}_{3} \mathrm{Si}_{2} \mathrm{H}_{2}$, experimentally observed and predicted by atomistic modelling to be around $10 \%[4,5]$, resulting in a drastic increase in reactive surface area and further oxidation and hydrogen production. When considering steam reactions, hydrogen is formed from an initial oxidation reaction, and so in practice limiting either the oxidation or hydride-formation reactions could greatly improve steam performance in this fuel material. 
$\mathrm{UB}_{2}$ enriched in ${ }^{11} \mathrm{~B}$ has been the source of burgeoning interest as a fuel material, as a result of its physical and neutronic properties. Recent modelling and experiment suggests that $\mathrm{UB}_{2}$ may be a significant ATF candidate in its own right $[6,7,8]$ with a uranium density of $11.6 \mathrm{~g} / \mathrm{cm}^{3}[9]$.

Furthermore, there remains the need to develop a burnable absorber (BA) concept for $\mathrm{U}_{3} \mathrm{Si}_{2}$ pellets. Gadolinium compounds have been shown to cause degradation of the $\mathrm{U}_{3} \mathrm{Si}_{2}$ phase, forming both uranium metal and USi phases; gadolinium is therefore not a credible candidate for homogeneous inclusion within $\mathrm{U}_{3} \mathrm{Si}_{2}[10]$.

One potential option is to utilise $\mathrm{UB}_{2}$ as a BA within $\mathrm{U}_{3} \mathrm{Si}_{2}$. It is possible to vary the enrichment of ${ }^{10} \mathrm{~B}$ such that the material will act as a BA in some core regions and a simple fuel in other regions.

Atomic scale modelling (Section 2.2) suggests that the addition of $\mathrm{UB}_{2}$ to $\mathrm{U}_{3} \mathrm{Si}_{2}$ may both allow for reactivity control and may potentially inhibit a mechanism that leads to the adverse steam reaction observed by Sooby-Wood et al. [3], thus preventing or slowing the rapid pulverisation of the material.

\section{Methodology}

\subsection{Fabrication Methodologies}

The primary goal of the experimental trials conducted at Manchester was to demonstrate the feasibility of $\mathrm{U}_{3} \mathrm{Si}_{2} / \mathrm{UB}_{2}$ composite materials under 'standard' sintering treatment. In this context, 'standard' refers to utilising similar powder preparation and sintering parameters to those employed in existing $\mathrm{U}_{3} \mathrm{Si}_{2}$ studies [1].

\subsubsection{Arc Melting}

Early trials of producing $\mathrm{U}_{3} \mathrm{Si}_{2}$-boron composites proceeded via the use of arc melting; combining elemental boron or a combination of elemental boron and silicon with $\mathrm{U}_{3} \mathrm{Si}_{2}$ and observing the material phases produced on cooling. Both methodologies produced similar results to previous work involving the arc melting of gadolinium with uranium silicide ??, with the $\mathrm{U}_{3} \mathrm{Si}_{2}$ phase breaking down to form silicon rich regions, alongside the formation of a uranium metal phase. This programme was halted after a small number of trials, and cold pressing and sintering of composite discs was investigated for further trials.

\subsubsection{Powder Production}

In order to introduce $\mathrm{UB}_{2}$ in a lower temperature and more controlled regime, $\mathrm{UB}_{2}$ and $\mathrm{U}_{3} \mathrm{Si}_{2}$ powders were combined and used to produce small discs. $\mathrm{UB}_{2}$ powder was produced by high energy ball milling an ingot of $\mathrm{UB}_{2}$ produced directly from arc-melting uranium metal and elemental boron. During this process, crystalline boron was seen to react particularly energetically to the process, and often shattered preventing its inclusion within the arc melted button. As such, boron was added until the required mass was reached for stoichiometry, assuming no uranium was lost during the process. Uranium silicide powder was produced following the method detailed within [10].

Tungsten carbide milling vessels and media were required to successfully mill $\mathrm{UB}_{2}$; the use of hardened steel tooling resulted in the impregnation of $\mathrm{UB}_{2}$ into both the vessel and milling media and the loss of a large volume of material. To counteract this, $0.01 \mathrm{~g}$ polyethylene-glycol (PEG) was added to each $50 \mathrm{ml}$ milling vessel for future runs, which proved successful with 
tungsten carbide mills but made little difference to the performance of hardened steel milling media.

Previous experience at Manchester has shown that the age of $\mathrm{U}_{3} \mathrm{Si}_{2}$ powder can have a significant impact on the sintering performance of green pellets produced from it, assumed to be through the formation of a thin silicon oxide layer on the powder surface. This has been observed even in very low $\mathrm{O}_{2}$ environments $\left(<1 \mathrm{ppm} \mathrm{O}_{2}\right)$. As the powder employed in these preliminary studies was around two weeks old, it was expected that discs produced from this material would be of reasonably low density and show large volumes of porosity.

\subsubsection{Cold Press and Sintering}

Several composite mixtures were produced ranging from pure $\mathrm{U}_{3} \mathrm{Si}_{2}$ to pure $\mathrm{UB}_{2}$. In order to observe phase instability when either $\mathrm{U}_{3} \mathrm{Si}_{2}$ or $\mathrm{UB}_{2}$ was the dominant phase, $10 \mathrm{wt} . \%$ and $90 \mathrm{wt} . \% \mathrm{UB}_{2}$ mixtures were studied, as well as a $50 \mathrm{wt} . \% \mathrm{UB}_{2}$ mixture. Powder milling, mixing and pressing were all performed within an atmosphere controlled argon glovebox, typically less than 1 ppm $\mathrm{O}_{2}$.

Powders were mechanically mixed by hand to maintain the stoichiometry of the desired mixtures, as it was observed during milling that each compound behaved differently within stainless steel and tungsten carbide milling vessels. $\mathrm{U}_{3} \mathrm{Si}_{2}$ behaves well in stainless steel, but a large fraction becomes unrecoverable within tungsten carbide vessels. $\mathrm{UB}_{2}$ responds in the opposite fashion. Hence hand mixing via rolling and shaking within a quartz vessel was used to blend the powders. This occasionally resulted in variations in local stoichiometry between the different uranium phases, particularly the $50 \mathrm{wt} . \%-50 \mathrm{wt} . \%$ mixture of $\mathrm{UB}_{2}$ and $\mathrm{U}_{3} \mathrm{Si}_{2}$. It proved relatively easy to identify these regions and remove them from further analysis, as they showed a significantly altered microstructure.

Powders were pressed into $6 \mathrm{~mm}$ diameter discs using a mechanical press to a pressure of $120 \mathrm{MPa}$. Die tooling was lubricated with zinc stearate to ease sample removal. Green discs all appeared to be well formed, although on handling with tweezers some damage occurred, particularly around the circumference of pellets. This was not unexpected given the use of milling lubricant, and did not prevent the use of these samples for further testing within this work. Later pellets were produced with a small mix of binding agent $\left(\right.$ PolyOx $\left.^{1}\right)$ which greatly improved green pellet robustness.

Composite and $\mathrm{U}_{3} \mathrm{Si}_{2}$ pellets were sintered within graphite crucibles utilising a graphitelined vacuum furnace. Tantalum beads and foil were used to limit contact between fuel materials and graphite, as well as acting as an oxygen getter during sintering. Vacuum was maintained at at least $10^{-3}$ mbar during sintering. Pellets were held at $1500^{\circ} \mathrm{C}$ for one hour, with shorter isothermal steps at $350{ }^{\circ} \mathrm{C}$ and $650{ }^{\circ} \mathrm{C}$ to remove remaining PEG and binder material. Pure $\mathrm{UB}_{2}$ pellets were sintered with a maximum temperature of $1800^{\circ} \mathrm{C}$, with a one hour hold time.

Sintered pellets were partially friable, as expected due to the age of the silicide powder employed, and had a relatively low density compared to typical targets for fuel: approximately 70$80 \%$. This large range in density is due to the non-standard geometry produced during the process, and the difficulty in employing pycnometry or immersion density measurements to porous materials. Density measured by pycnometry was high (above $90 \%$ ) indictating a large volume of open porosity, consistent with gas evolution during the sintering stage. $\mathrm{UO}_{2}$ is typically sintered with a target density of $95 \%$ of theoretical density, which is also a general target for sintered

\footnotetext{
${ }^{1}$ Polyethylene Oxide M.W. 100,000
} 
$\mathrm{U}_{3} \mathrm{Si}_{2}$ in order to accomodate fission induced swelling of the fuel and hence reduce the strain in the cladding [11]. The pellets produced here were significantly below this value. This was not considered problematic for the current study, as microstructural examination and phase identification (Section 3.1) could still be conducted without issue, and both reference silicide and composite materials appeared to be broadly similar in sintering behaviour.

\subsection{Atomic Scale Modelling}

Density functional theory based calculations were performed at Bangor University using the Vienna Ab-initio Software Package (VASP) [12, 13, 14]. Projector augmented-wave potentials [15] were used with the GGA-PBE exchange correlation [16] supplied with the software.

Simulations of $\mathrm{UB}_{2}$ were performed using a $4 \times 4 \times 3$ super-cell of the $P 6 / \mathrm{mmm}$ unit-cell (similar to previous work on the $\mathrm{ZrB}_{2}$ system [17]). A $4 \times 4 \times 4$ gamma centred $k$-point grid was used. Simulations were performed under constant pressure allowing both cell volume and shape to change. The electronic self consistent field cut-off criterion was set to $10^{-4} \mathrm{eV}$ and the geometry optimisation cut-off criterion was set to $10^{-3} \mathrm{eV}$. The cut-off energy was set to $400 \mathrm{eV}$. A firstorder Methfessel-Paxton [18] method was used for smearing of the bands with a width of $0.1 \mathrm{eV}$. In accordance with the results from Burr et al. [7], no Hubbard parameter was applied to the U f-electrons.

In previous work, the solubility of $\mathrm{H}_{2}$ into $\mathrm{U}_{3} \mathrm{Si}_{2}$ was investigated [5], highlighting that the reaction was exothermic forming $\mathrm{U}_{3} \mathrm{Si}_{2} \mathrm{H}_{2}$ with an associated swelling of $10 \%$. In this work, the solubility of $\mathrm{H}_{2}$ into $\mathrm{UB}_{2}$ is considered and compared to the previous results in order to help explain the experimentally observed differences in behaviour between $\mathrm{UB}_{2}$ and $\mathrm{U}_{3} \mathrm{Si}_{2}$.

$\mathrm{H}$ solution onto five interstitial sites was considered:the $1 \mathrm{~b}-\left(0,0, \frac{1}{2}\right), 2 \mathrm{c}-\left(\frac{1}{3}, \frac{2}{3}, 0\right), 2 \mathrm{~d}-\left(\frac{1}{3}, \frac{2}{3}, \frac{1}{4}\right)$, $3 \mathrm{f}-\left(\frac{1}{2}, 0,0\right)$ and $6 \mathrm{i}-\left(\frac{1}{2}, \frac{1}{2}, \frac{1}{4}\right)$ sites (all with Wyckoff notation and fractional coordinates). The solution enthalpy was considered through the following simple reaction:

$$
\frac{1}{2} H_{2} \rightarrow H_{i}
$$

The $\mathrm{H}_{2}$ molecule was modelled as a single dimer in a large cell and the binding energy was found to be in good agreement with the experimental observation $(-2.27 \mathrm{eV}$ per atom). The temperature dependent entropy for the $\mathrm{H}_{2}$ molecule was taken from the NIST-JANAF tables [19].

\subsection{Atomic scale modelling of hydrogen in $U B_{2}$}

To understand the potential improvement related to the addition of $\mathrm{UB}_{2}$ to $\mathrm{U}_{3} \mathrm{Si}_{2}$, atomic scale modelling based on density functional theory has been used to assess the propensity for hydrogen solution into $\mathrm{UB}_{2}$ and compare this behaviour with $\mathrm{U}_{3} \mathrm{Si}_{2}$. The experimental results suggest that the two main phases do not react with each-other and previous calculations show that the potential for defects resulting from stoichiometry deviations are very low in concentration in the $\mathrm{UB}_{2}$ system - and it is therefore only necessary to carry out a simple hydrogen solution through interstitial defects computations.

Solution of hydrogen into $\mathrm{UB}_{2}$ was found to proceed endothermically onto all considered interstitial sites. The lowest solution enthalpy was computed to be $0.81 \mathrm{eV}$ onto the $2 \mathrm{~d}-\left(\frac{1}{3}, \frac{2}{3}, \frac{1}{4}\right)$ site (with solution onto the $1 \mathrm{~b}, 2 \mathrm{c}, 3 \mathrm{f}$ and $6 \mathrm{i}$ sites proceeding with $1.36 \mathrm{eV}, 0.98 \mathrm{eV}, 1.82 \mathrm{eV}$ and $1.12 \mathrm{eV}$, respectively). Compared to $\mathrm{U}_{3} \mathrm{Si}_{2}$, which reacts exothermically with $\mathrm{H}_{2}, \mathrm{UB}_{2}$ is not expected to accommodate any significant concentration of hydrogen produced as a result of the oxidation of the fuel or the cladding material in the event of cladding failure. In a similar manner 


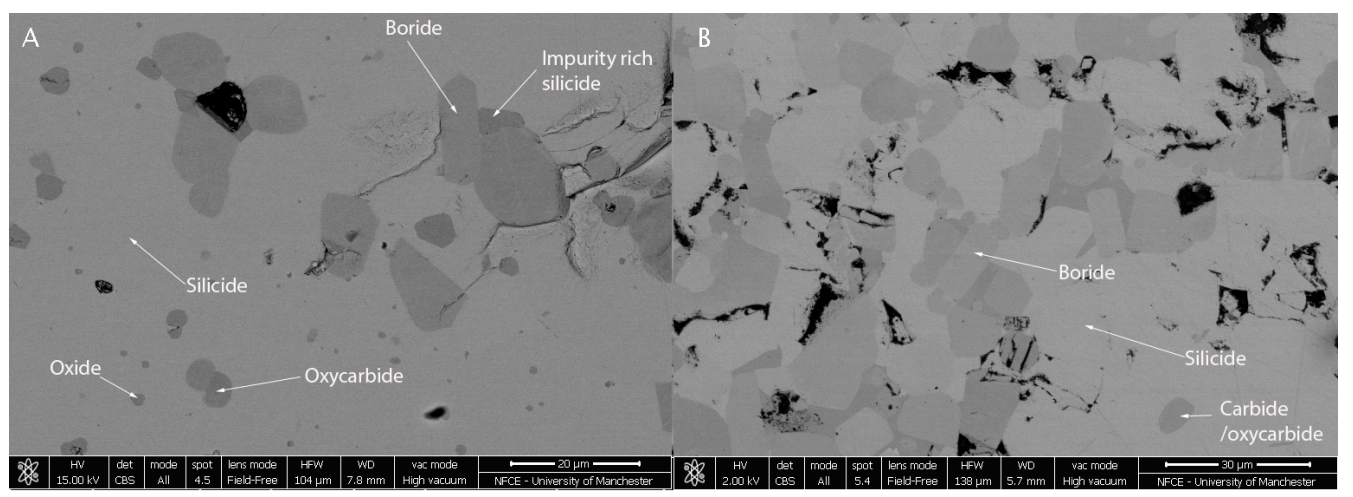

Figure 1: Microstructure of $10 \mathrm{wt} \%$ (A) and 50wt $\%$ (B) $\mathrm{UB}_{2}$ discs produced using backscatter detector

to $\mathrm{U}_{3} \mathrm{Si}_{2}$, increases in temperature are shown to make the solution of $\mathrm{H}_{2}$ into $\mathrm{UB}_{2}$ even less favourable as a result of the increasing contribution of the vibrational entropy of the $\mathrm{H}_{2}$ molecule [5].

The volume change associated with a single hydrogen atom entering a 144 atom supercell of $\mathrm{UB}_{2}(0.7$ at. $\%)$ is $0.2 \%$. Expansion in the $\mathrm{a} / \mathrm{b}$-axis is three times larger than in the c-axis indicating a large anisotropy. Given the concentration of hydrogen in solution within the $\mathrm{UB}_{2}$ lattice is expected to be more than ten orders of magnitude lower than this concentration according to the laws of mass action [20], the volume change as a result of hydrogen incorporation is not expected to be a factor in the degradation of $\mathrm{UB}_{2}$ when exposed to aqueous environs.

\section{Experimental Results}

\subsection{Microstructure and Phase Analysis}

The microstructure of composite pellets and the phases present were examined via electron microscopy and X-ray diffraction (XRD) of powdered pellet sections.

SEM micrographs of a $90 \mathrm{wt} . \%-10 \mathrm{wt} . \%$ and $50 \mathrm{wt} . \%-50 \mathrm{wt} . \% \mathrm{U}_{3} \mathrm{Si}_{2}-\mathrm{UB}_{2}$ discs are shown in Figure $1 \mathrm{~A}$ and $\mathrm{B}$, respectively. Both pellets show $\mathrm{UB}_{2}$ regions well sintered within a $\mathrm{U}_{3} \mathrm{Si}_{2}$ matrix. There are also small inclusions of uranium oxide and uranium oxy-carbide within the silicide. From XRD these have been identified as $\mathrm{UO}_{2}$ and $\mathrm{UC}_{0.75} \mathrm{O}_{0.25}$. The $\mathrm{UCO}$ phase is visible in $\mathrm{UB}_{2}$ containing samples following milling, while a small mass of U-metal was observed in un-milled $\mathrm{UB}_{2}$, suggesting the $\mathrm{UB}_{2}$ was slightly uranium rich following arc melting, and reacted with the carbide milling vessel during powder processing. This phase was identified prior mixing with $\mathrm{U}_{3} \mathrm{Si}_{2}$, and it is therefore not indicative of a potentially problematic reaction between the $\mathrm{UB}_{2}$ and $\mathrm{U}_{3} \mathrm{Si}_{2}$ phases.

Due to both the porosity present within the samples, and the presence of the additional phases, the experimental conclusions drawn from these samples are largely limited to the investigation of interfacial boundary layers between the $\mathrm{UB}_{2}$ and $\mathrm{U}_{3} \mathrm{Si}_{2}$ phases. Previous work on burnable poisons in $\mathrm{U}_{3} \mathrm{Si}_{2}$ has identified that the $\mathrm{U}_{3} \mathrm{Si}_{2}$ phase can be almost entirely disrupted from small quantities of gadolinium [10]. Analysis of the $\mathrm{U}_{3} \mathrm{Si}_{2}$ phase following introduction of $\mathrm{UB}_{2}$ is therefore important to ensure that it remains stable following pressing and sintering. 


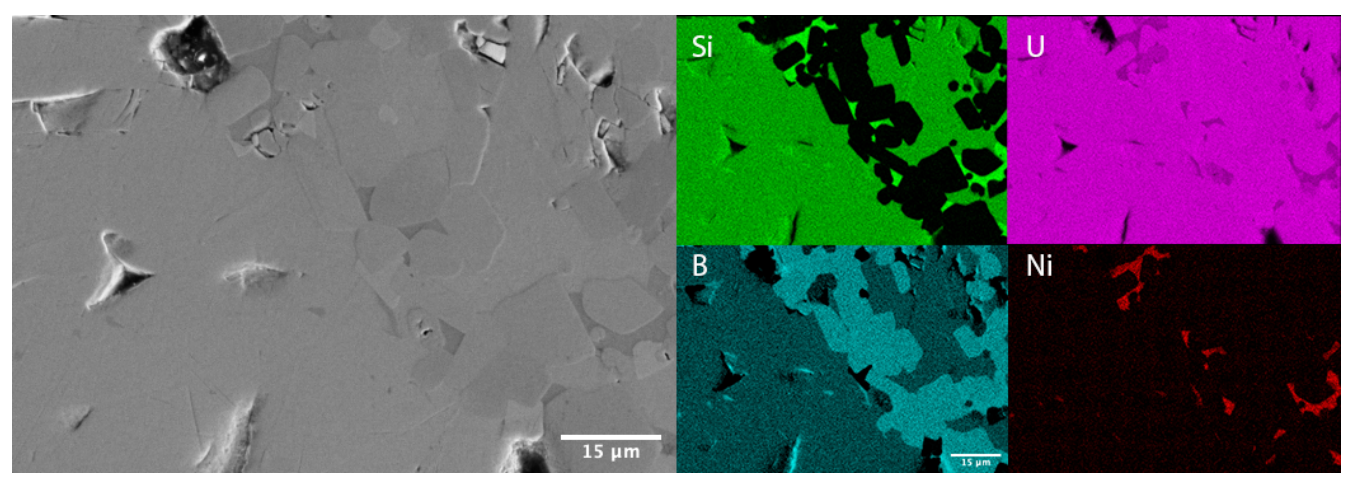

Figure 2: Elemental mapping of $50 \mathrm{wt} \% \mathrm{UB}_{2}$ composite pellet, produced from EDX

Energy Dispersive X-ray Spectroscopy (EDX) was employed to determine the microstructural segregation of the two phases (Figure 2). Boride and silicide phases appear distinct according to SEM-EDX analysis.

Although some regions of $\mathrm{Ni}$ and $\mathrm{Fe}$ impurities exist, and silicon and boron-poor areas are visible, these are not generally co-located at the boundaries between silicide and boride phases. $\mathrm{Ni}$ impurities result from the original source uranium, which was nickel plated and mechanically ground prior to use. Fe contamination likely resulted from pre-crushing of the arc-melted $\mathrm{UB}_{2}$ material, which was achieved via impact with a steel weight. Both are present in Figure 2 in concentrations less that 0.5 at $\%$. These Impurities appear to cause the formation of silicon-rich silicide regions, although these do not appear to be USi and were not present on XRD analysis.

EDX line-profile analysis of silicide-boride grain boundaries shows a sharp transition between the two phases, up to the resolution of the instrument, suggesting that the phases do not interact at the pellet sintering temperature employed in this study.Some small quantities of uranium metal/uranium carbide/oxycarbide ${ }^{2}$ are visible in Figure 2, but these appear to be located very close to larger volumes of impurities and oxide grains. Their formation is not consistently on boride/silicide boundaries. In addition, silicon rich regions visible in Figure 2 are close to the boundary with the UO/UC phases already identified: most likely formed during the preferential oxidation of $\mathrm{U}$ over $\mathrm{Si}$. Note that the boron signal visible on Figure 2 within silicon rich regions is a result of the overlapping boron, carbon and uranium peaks present at these X-ray energies, and below a reasonable limit of detection for boron using this technique

Phase analysis was performed via XRD on initial materials, powder mixes and sintered pellets which were crushed prior to analysis. XRD patterns of 50-50 composite material are presented in Figure 3 as representative. The raw $\mathrm{UB}_{2}$ material produced shows a small quantity of uranium metal present within the material, suggesting that the produced bulk is slightly uranium rich ( $\mathrm{UB}_{2}$ is a line compound [7]), bulk $\mathrm{U}_{3} \mathrm{Si}_{2}$ appears phase pure. Powder blended material show small quantities $(<5 \%)$ of uranium oxy-carbide $\left(\mathrm{UC}_{0.75} \mathrm{O}_{0} .25\right)$ and carbide $\left(\mathrm{UC}_{2}\right.$ phases $)$, likely resulting from the interaction of uranium metal within the initial boride material reacting with the tungsten carbide milling vessel during the high energy milling process.

\footnotetext{
${ }^{2} \mathrm{EDX}$ is unable to distinguish between uranium and carbon due to overlapping low energy peaks, and surface oxygen
} is overestimated using the technique 


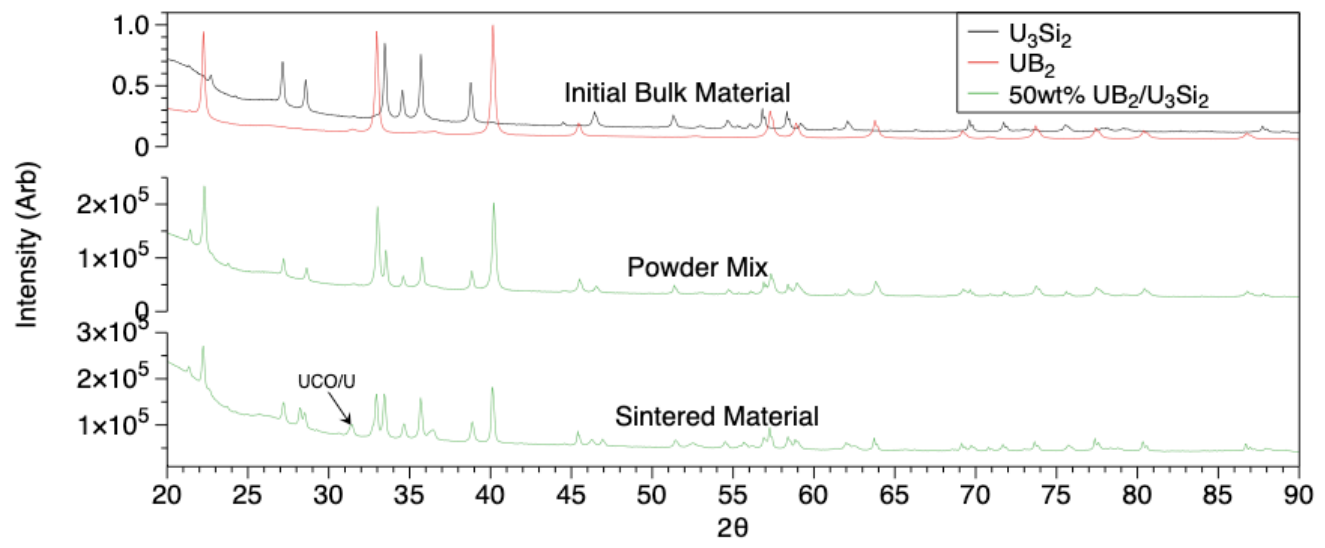

Figure 3: XRD Patterns from initial bulk materials (top), powder blends (middle) and sintered material (bottom). Uranium metal peaks are denoted with an asterisk

\section{Discussion}

The manufacture of test specimens in the $\mathrm{U}_{3} \mathrm{Si}_{2}-\mathrm{UB}_{2}$ system suggest that these composite materials are stable during standard cold press and sintering preparations. It is particularly encouraging to note that the $\mathrm{UB}_{2}$ rich samples produced sintered to similar densities and physical robustness as the $\mathrm{U}_{3} \mathrm{Si}_{2}$ material utilised in the study. A key challenge with employing $\mathrm{UB}_{2}$ as a monolithic fuel form is expected to be that of sintering; $\mathrm{UB}_{2}$ has a melting point of over $2400{ }^{\circ} \mathrm{C}$, and similar diboride compounds such as $\mathrm{ZrB}_{2}$ typically do not fully densify without the use of sintering aids or pressurised sintering techniques [22]. The composites produced here appear to have successfully incorporated $\mathrm{UB}_{2}$ grains at lower temperatures than are necessary for sintering of pure $\mathrm{UB}_{2}$. Although several minor phases and inclusions were noted within the material microstructure, the source of these appears to be understood and future studies would likely reduce or remove these via an alternative uranium source and coated steel components.

Modelling of hydrogen solubility within $\mathrm{UB}_{2}$ demonstrates that the reaction is endothermic and has a predicted volume change of less than $10 \%$ of that predicted for $\mathrm{U}_{3} \mathrm{Si}_{2}$. The inclusion of a $\mathrm{UB}_{2}$ phase may therefore offer some improvements to the steam performance of $\mathrm{U}_{3} \mathrm{Si}_{2}$ fuel, without compromising on the improved thermal performance or uranium density which are key drivers of $\mathrm{U}_{3} \mathrm{Si}_{2}$ development. This will rely on the interaction of the phases within a complex steam environment and detailed experimental data is required to properly assess potential improvements.

The formation of composite fuel pellets is encouraging beyond any potential water performance improvements; $\mathrm{UB}_{2}$ may be a promising fuel material in its own right, but has historically been considered commercially unattractive due to the need to procure enriched boron for fabrication and as such has been the subject of limited study. Limited modern atomistic modelling studies [6] and historic experimental investigations [23] demonstrate attractive thermal properties for example, and it has a higher uranium density than $\mathrm{U}_{3} \mathrm{Si}_{2}$ and $\mathrm{UO}_{2}$. The use of smaller weight percentages of $\mathrm{UB}_{2}$ within a $\mathrm{U}_{3} \mathrm{Si}_{2}$ matrix goes some way towards addressing this concern, while arriving at a fuel form which potentially retains the benefit of both materials, and solves the issue of $\mathrm{BA}$ addition to $\mathrm{U}_{3} \mathrm{Si}_{2}$. 


\section{Conclusions}

Several composite fuel discs were produced, containing a range of $\mathrm{U}_{3} \mathrm{Si}_{2}$ and $\mathrm{UB}_{2}$ phases. Despite the incorporation of some impurities and minor phases, the two materials appear to retain phase stability during sintering, and composite material sintering performance was similar to that of reference $\mathrm{U}_{3} \mathrm{Si}_{2}$ discs produced for this study. The successful incorporation of a boron compound into a $\mathrm{U}_{3} \mathrm{Si}_{2}$ pellet provides one solution to the need to add burnable absorber material to fuel pellets. Hydrogen solubility in $\mathrm{UB}_{2}$ is predicted to be low indicating a potential improvement of the material's behaviour when exposed to steam compared to monolithic $\mathrm{U}_{3} \mathrm{Si}_{2}$.

\section{Data Availability}

The raw/processed data required to reproduce these findings cannot be shared at this time as the data also forms part of an ongoing study

\section{References}

[1] J.M. Harp, P.A. Lessing, B.H. Park, J. Maupin, DOE-NE Report, INL/CON-13-28403 (2013).

[2] F. Cappia, J.M. Harp, J. Nucl. Mater. 518 (2019) 62-79.

[3] E. Sooby-Wood, J.T. White, C.J. Grote, A.T. Nelson, J. Nucl. Mater. 501 (2018) 404-412.

[4] S. Măsková, K. Miliyanchuk, L. Havela, J. Nucl. Mater., 487 (2017) 418-423.

[5] S.C Middleburgh, A. Claisse, D.A. Andersson, R.W. Grimes, P. Olsson, S. Maskova, J. Nucl. Mater. 501 (2018) 234-237.

[6] E. Jossou, L. Malakkal, B. Szpunar, D. Oladimeji, J.A. Szpunar, J. Nucl. Mater. 490 (2017) 41-48.

[7] P.A. Burr, E. Kardoulaki, R. Holmes, S.C. Middleburgh, J. Nucl. Mater. 513 (2019) 45-55.

[8] E. Jossou, D. Oladimeji, L. Malakkal, S. Middleburgh, B. Szpunar, J. Szpunar, J. Nucl. Mater. 494 (2017) $147-156$.

[9] S.J.L. Snelgrove, G.L. Hofman, C.L. Trybus, T.C. Wiencek, OSTI Report, DE97001401; NTIS; US Govt. Printing Office Dep (1996).

[10] J.Turner,J. Buckley, G. Phillips, T.J. Abram, J. Nucl. Mater., 509 (2018) 204-211.

[11] S.C. Middleburgh, R.W. Grimes, K.H. Desai, P.R. Blair, L. Hallstadius, K. Backman, P. Van Uffelen, J. Nucl. Mater., 427 (2012) 359-363.

[12] G. Kresse and J. Hafner. Ab initio molecular dynamics for liquid metals. Phys. Rev. B, 47:558, 1993.

[13] G. Kresse and J. Hafner. Ab initio molecular-dynamics simulation of the liquid-metal-amorphous-semiconductor transition in germanium. Phys. Rev. B, 49:14251, 1994.

[14] G. Kresse and J. Furthmller. Efficiency of ab-initio total energy calculations for metals and semiconductors using a plane-wave basis set. Comput. Mat. Sci., 6:15, 1996.

[15] P. E. Blochl. Projector augmented-wave method. Phys. Rev. B, 50:17953, 1994.

[16] J. P. Perdew, K. Burke, and M. Ernzerhof. Generalized gradient approximation made simple. Phys. Rev. Lett., 77:3865, 1996.

[17] S.C. Middleburgh, D.C. Parfitt, P.R. Blair, R.W. Grimes, J. Am. Ceram. Soc. (2011) 94 2225-2229.

[18] M. Methfessel, A. Paxton, Phys. Rev. B 40 (1989) 3616-3621.

[19] M.W. Chase Jr., C.A. Davies, J.R. Downey Jr., D.J. Frurip, R.A. McDonald, A.N. Syverud, NIST JANAF Thermochemical Tables (1985) 20899,

[20] A. Chroneos, R.W. Grimes, Appl. Phys. Lett., 91 (2007) 192106.

[21] J.M Harp, P.A. Lessing, R. E. Hoggan, J. Nucl. Mater., 466 (2015) 728-738

[22] Chamberlain, A. L., Fahrenholtz, W. G., Hilmas, G. E., J. Am. Ceram. Soc., 89 (2006) 450-456

[23] Flotow, H. E., Osborne, D. W., OHare, P. A. G., Settle, J. L., Mrazek, F. C., Hubbard, W. N., The Journal of Chemical Physics, 51(2) (1969), 583592. 